\title{
Optimalisasi Perawatan Mesin Press Dengan Metode Failure Mode Effect Analysis (FMEA)
}

\author{
Ribut Santoso*, Idham Halid Lahay**, Stella Junus***,Yolanda Lapai****ł \\ *,**,***,**** Universitas Negeri Gorontalo, Jl. Jenderal Sudirman No.6 Kota Gorontalo, Indonesia 96128 \\ (ributsantoso013@gmail.com, idham-lahay@ung.ac.id, stellajunus@ung.ac.id, yolandalapai7@gmail.com)
}

†enulis Koresponden; Yolanda Lapai, Tel: +62 8524133 9491, yolandalapai7@gmail.com

Diterima: 04.08.2020 Disetujui: 19.08.2020 Diterbitkan: 01.05.2021

\begin{abstract}
Abstrak- Sistem perawatan yang dilakukan selama ini adalah bersifat breakdown maintenance yaitu pemeliharaan yang dilakukan setelah mesin mengalami kerusakan. Sistem ini belum memberikan data akurat kapan suatu mesin atau komponen mengalami kerusakan, sehingga strategi yang tepat untuk menjaga mesin tetap beroperasi adalah menentukan interval waktu perawatan yang optimal. Hasil analisis yang dilakukan dengan menggunakan metode Failure Mode and Effect Analysis (FMEA) maka didapat komponen kritis pada mesin screw press yaitu komponen worm screw, besi shaft dan press cage. Hasil perhitungan diperoleh waktu penggantian komponen worm screw 32 hari, besi shaft 68 hari, press cage 48 hari pada Mesin Screw Press 1. Untuk Mesin Screw Press 2 komponen worm screw 52 hari, besi shaft 128 hari, press cage 52 hari. Untuk Mesin Screw Press 3 komponen worm screw dilakukan penggantian selama 56 hari, besi shaft 104 hari, press cage 64 hari. Untuk Mesin Screw Press 4 pada komponen worm screw dilakukan penggantian selama 56 hari, besi shaft 72 hari, press cage 74 hari. Untuk Mesin Screw Press 5 pada komponen worm screw dilakukan penggantian selama 50 hari, besi shaft 80 hari, press cage 92 hari. Dan untuk Mesin Screw Press 6 pada komponen worm screw dengan interval waktu penggantian selama 52 hari, besi shaft 72 hari dan press cage 58 hari.
\end{abstract}

Kata Kunci : FMEA, mean time to failure, mean time to repair, downtime, age replacement

\section{Optimization of the Press Machines Maintenance Using Failure Mode Effect Analysis (FMEA) Method}

\begin{abstract}
Abstrak- Commonly, the maintenance system used is breakdown maintenance which refers to the maintenance that is performed after those machines was broken. This system does not provide accurate data on a precise time when machines or its component would be broken. Thus a proper strategy to keep the machines operating is performed by determining the optimum time interval of the maintenance process. The study analysis method using Failure Mode Effect Analysis (FMEA) reveals that critical components at screw press machine are worm screw, shaft iron, and press cage. The calculations show that replacement time for Worm Screw component is 32 days, Shaft Iron is 68 days, and Press Cage is 48 days at Screw Press Machine 1. Then, for Screw Press Machine 2 are 52 days for Worm Screw component, 128 days for shaft Iron and 52 days for Press Cage. Next, for Screw Press Machine are 56 days for Worm Screw Component, 104 days for Shaft Iron and 64 days for Press Cage. Then, for Screw Press Machine 4 are 56 days for Worm Screw component, 72 days for Shaft Iron and 74 days for Press Cage. Then, for Screw Press Machine 5 are 50 days for Worm Screw component, 80 days for Shaft Iron and 92 days for Press Cage and Screw Press Machine 6 are 52 days for Worm Screw component, 72 days for Shaft Iron and 58 days for Press Cage.
\end{abstract}

Keywords : FMEA, mean time to failure, mean time to repair, downtime, age replacement 


\section{Pendahuluan}

Breakdown maintenance merupakan srategi perawatan yang sangat kasar dan kurang baik karena dapat menimbulkan biaya tinggi, kondisi mesin atau komponen tidak diketahui dan tidak adanya perencanaan waktu tenaga kerja maupun biaya yang baik [1], akibat dari penerapan sistem perawatan breakdown, seringkali terjadi kerusakan komponen dalam melakukan pergantian [2]. Kemudian perawatan mesin berkembang dengan sistem preventive maintenance. Preventive maintenance bertujuan untuk mencegah kerusakan mesin yang sifatnya mendadak dan meningkatkan reliability mesin [3].

PT. XYZ merupakan perusahaan yang bergerak di bidang usaha pengolahan minyak kelapa sawit di Sulawesi Tengah yang mengolah tandan buah segar menjadi produk berupa Crude Palm Oil (CPO) dan Palm Kernel (PK) yang berkapasitas 60 ton/jam. Mesin screw press salah satu mesin yang mendukung aktivitas proses produksi. Perusahaan memakai 6 mesin scres press yang berfungsi sebagai pengempa buah sawit dengan kapasitas terpasang 15 ton/jam pada masing-masing mesin.

Sistem perawatan yang dilakukan selama ini oleh perusahaan adalah bersifat penerapan breakdown maintenance sehingga perusahaan hanya mengganti komponen yang rusak tanpa memperhatikan tingkat keandalanya. Sistem ini belum dapat memberikan data yang akurat tentang kapan suatu mesin atau komponen akan mengalami kerusakan serta dalam penggunaan mesin screw press perusahaan belum menerapkan sistem pergantian penjadwalan dalam pengoprasian mesin tersebut, sehingga mesin akan digunakan sesuai dengan keinginan operator. Maka dampak yang ditimbulkan yaitu tingkat keandalan mesin akan menurun. Tindakan perawatan mesin digunakan untuk dapat mencegah terjadinya kerusakan secara mendadak. Strategi yang tepat untuk menjaga mesin agar dapat beroperasi adalah dengan cara menentukan interval waktu perawatan peralatan yang optimal yang nantinya akan dibuat dalam bentuk jadwal perawatan. Untuk itu metode preventive maintenance digunakan untuk merencanakan persediaan sparepart komponen mesin yang sering mengalami kerusakan.

Tujuan yang ingin dicapai dalam penelitian ini adalah sebagai berikut:

1. Berapa besar perbandingan realibilty sebelum dan sesudah melaksanakan preventif maintenance.

2. Menentukan persediaan sparepart komponen kritis mesin screw press.

\subsection{Perawatan}

Perawatan dianggap merupakan kegiatan sia-sia yang membuang waktu, tenaga, dan uang. Padahal kegiatan perawatan merupakan kegiatan yang bertujuan untuk melestarikan dan memperlancar jalannya proses produksi yang telah direncanakan sebelumnya. Kelancaran proses produksi suatu industri, kualitas atau mutu suatu industri tidak lepas dari salah satu indikasi peranan peralatan. Pentingnya sebuah peralatan harus dijaga dengan baik, karena baiknya sebuah peralatan dilihat dari bagaimana penerapan perawatan/perbaikan [4].

Prosedur dalam perencanaan pemeliharaan terencana yaitu meliputi pembuatan daftar sarana, selanjutnya kita harus menentukan bagaimana aset atau sarana ini dipelihara. Perawatan yang dilaksanakan dalam periode waktu yang tetap dengan kriteria di berbagai tahap produksi tujuanya agar produk yang dihasilkan sesuai rencana, baik mutu, biaya, maupun ketepatan waktu [5]. Suatu jadwal pemeliharaan harus dibuat bagi setiap mesin atau peralatan yang telah ditentukan agar mendapatkan pemeliharaan pencegahan terencana. Sistem ini dapat dimulai dengan menggunakan pemeliharaan pencegahan terencana bagi beberapa mesin dan sesudah didapatkan pengalaman dalam penggunaan jadwal [6].

\subsection{Failure Mode Effect Analysis (FMEA)}

FMEA yang merupakan kepanjangan dari Failure Modes and Effects Analysis atau disebut juga dengan analisis mode-mode kegagalan dan efek-efeknya pertama-tama dipergunakan pada tahun 1960-an dalam industri penerbangan dan sekarang merupakan teknik yang digunakan sebagian besar sektor industri. FMEA merupakan metode obyektif untuk mengevaluasi desain sistem [7]. FMEA adalah sebuah metode evaluasi kemungkinan terjadinya sebuah kegagalan dari sebuah sistem, desain, proses atau servis untuk dibuat langkah penanganannya [8]. FMEA digunakan untuk mencari penyebab dan efek yang ditimbulkan dari kegagalan yang terjadi [9].

Realiability adalah angka yang menunjukan keandalan alat dalam arti alat mampu dioperasikan terus menerus selama periode tertentu tanpa mengalami gangguan atau kerusakan [10]. Realiability juga dapat dikuantifikasi dengan menggunakan rata-rata banyaknya kegagalan dalam jangka waktu tertentu [11]. Avaibility adalah probabilitas suatu komponen atau sistem menunjukan kemampuan yang diharapkan pada suatu waktu tertentu. Ketika dioperasikan dalam kondisi operasional tertentu [12].

\section{Metodologi}

\subsection{Pengumpulan Data}

Pengumpulan data diambil di PT. XYZ data historis kerusakan mesin screw press periode Januari 2014 
April tahun 2017 yang dibutuhkan untuk menunjang penelitian ini. Adapun data yang digunakan meliputi :

1. Data mesin screw press dan komponenkomponennya

2. Data downtime dan kerusakan mesin screw press yang terjadi selama 4 tahun yaitu dari tahun 2014 sampai dengan 2017.

3. Data penyebab kegagalan beserta efek yang ditimbulkan akibat kegagalan.

4. Biaya kegagalan, meliputi harga komponen, ongkos tenaga kerja, dan biaya produksi yang hilang akibat perbaikan.

\subsection{Tahap Pengolahan Data}

Adapun tahapan dalam pengolahan data yang dilakukan yaitu sebagai berikut:

1. Failure Modes and Effect Analysis (FMEA) disusun berdasarkan fungsi komponen yang kemudian dapat ditentukan berbagai penyebab kegagalan yang menimbulkan kegagalan serta dampak yang diakibatkan dari kegagalan tersebut. Kemudian menentukan urutan nilai RPN (Risk Priority Number) dari yang tertinggi hingga yang paling rendah. Nilai RPN tertinggi dapat diartikan bahwa komponen tersebut membutuhkan penanganan yang segera.

2. Pengolah data tahap awal ini yaitu menentukan nilai selang waktu antar kerusakan dengan cara menghitung terus nilai MTTF (Mean Time To Failure) dan MTTR (Mean Time To Repair).

3. Penentuan index of fit. Pada tahap ini ditentu- kan index of fit pada masing-masing komponen mesin screw pres. Baik untuk data MTTF maupun data MTTR yaitu dengan cara mencari nilai R (index of fit) yang terbesar disetiap distribusi (Eksponensial. Lognormal, Normal, Weibull) yang akan dipilih.

4. Uji goodnes of fit. Fungsi dari pada uji goodnes of fit yaitu untuk menentukan apakah distribusi yang dipilih sudah sesuai.

5. Penentuan selang waktu penggantian pencegahan dan pemeriksaan. Selang waktu penggantian pencegahan dihitung berdasarkan umur penggantian optimal dengan kriteria minimasi downtime. Dari hasil perhitungan komponen (tp) dipilih tp dengan nilai total downtime $(\mathrm{D}(\mathrm{tp}))$ terkecil.

6. Penghitungan nilai ketersediaan (availability) total.

7. Penghitungan nilai keandalan (reliability).

\section{Hasil dan Pembahasan}

Tahap pertama dalam pengolahan data yaitu menentukan komponen kritis pada 6 mesin screw press menggunakan metode FMEA dengan cara memberikan tabel FMEA yang telah dirancang dan melakukan wawancara langsung pada mekanik stasiun mesin screw press yang berfungsi untuk menentukan komponen kritis yang akan dibuatkan interval waktu pergantian. Data ini diperoleh melalui observasi langsung serta wawancara dengan bagian mekanik yang ada pada stasiun mesin press screw yang berjumlah 3 orang. Tabel 1 merupakan hasil nilai ratarata RPN (Risk Priority Number) yang diberikan oleh

Tabel 1. Risk Priority Number yang dikumpulkan dari wawancara dengan para mekanik

\begin{tabular}{|c|c|c|c|c|c|}
\hline No & Nama Komponen & $\begin{array}{l}\text { RPN } \\
\text { M1 }\end{array}$ & $\begin{array}{l}\text { RPN } \\
\text { M2 }\end{array}$ & $\begin{array}{l}\text { RPN } \\
\text { M3 }\end{array}$ & $\begin{array}{l}\text { Rata- } \\
\text { Rata }\end{array}$ \\
\hline 1 & Besi Shaft VCN DIA $6^{\circ}$ x $1220 \mathrm{MM}$ & 350 & 320 & 280 & $317 *$ \\
\hline 2 & Besi Shaft VCN DIA $6^{\circ}$ x $100 \mathrm{MM}$ & 350 & 320 & 280 & $317 *$ \\
\hline 3 & Thrust Bearing 29420 E SKF & 175 & 180 & 224 & 193 \\
\hline 4 & Roller Bearing 22220 E/C3 SKF & 210 & 270 & 100 & 193 \\
\hline 5 & Roller Bearing SKF 22220 E/C3 SKF & 210 & 216 & 180 & 202 \\
\hline 6 & Worm Screw L (Left Side-P/N.14.2) & 320 & 256 & 280 & $285^{*}$ \\
\hline 7 & Worm Screw R (Left Side-P/N.14.2) & 320 & 256 & 280 & $285^{*}$ \\
\hline 8 & Press Cage P/N 16 For 15 & 280 & 144 & 320 & $248 *$ \\
\hline 9 & Spur Gear & 90 & 200 & 72 & 121 \\
\hline \multicolumn{5}{|c|}{ Jumlah } & 2161 \\
\hline
\end{tabular}


ketiga mekanik pekerja pada bagian stasiun mesin screw press. Ketiga orang mekanik ini memberikan besarnya nilai untuk ketiga penelitian yaitu severty $(S)$, Ocurence $(O)$, Detection $(D)$ dari masing-masing komponen. Hasil penilaian dari ketiga orang mekanik akan di rata-ratakan sehingga mendapatkan nilai kritis pada komponen mesin screw press. Prioritas perbaikan diberikan ketiga kasus kegagalan yang me-

Tabel 2. Frekuensi Kerusakan Mesin Screw Press Tahun 2014-1017

\begin{tabular}{ccccc}
\hline $\begin{array}{c}\text { Nama } \\
\text { Komponen }\end{array}$ & $\begin{array}{c}\text { Worm } \\
\text { Screw }\end{array}$ & $\begin{array}{c}\text { Besi } \\
\text { Shaft }\end{array}$ & $\begin{array}{c}\text { Press } \\
\text { Cage }\end{array}$ & Jumlah \\
\hline Mesin SP1 & 9 & 4 & 6 & 19 \\
Mesin SP2 & 6 & 4 & 5 & 15 \\
Mesin SP3 & 6 & 4 & 4 & 14 \\
Mesin SP4 & 8 & 4 & 5 & 17 \\
Mesin SP5 & 9 & 4 & 5 & 18 \\
\hline
\end{tabular}

Tabel 3. Hasil perhitungan interval pemeriksaan dan penggantian komponen kritis

\begin{tabular}{|c|c|c|c|}
\hline $\begin{array}{l}\text { Nama } \\
\text { Mesin }\end{array}$ & $\begin{array}{c}\text { Nama } \\
\text { Komponen } \\
\text { Kritis } \\
\end{array}$ & $\begin{array}{c}\text { Interval } \\
\text { Penggantian } \\
\text { (Hari) }\end{array}$ & $\begin{array}{c}\text { Interval } \\
\text { Pemeriksaan } \\
\text { (Jam) }\end{array}$ \\
\hline \multirow{3}{*}{$\begin{array}{l}\text { Mesin } \\
\text { Screw } \\
\text { Pres } 1\end{array}$} & $\begin{array}{l}\text { Worm } \\
\text { Screw }\end{array}$ & 32 & 58 \\
\hline & Besi Shaft & 68 & 83 \\
\hline & Press Cage & 48 & 59 \\
\hline \multirow{3}{*}{$\begin{array}{l}\text { Mesin } \\
\text { Screw } \\
\text { Pres } 2\end{array}$} & $\begin{array}{l}\text { Worm } \\
\text { Screw }\end{array}$ & 52 & 48 \\
\hline & Besi Shaft & 128 & 74 \\
\hline & Press Cage & 52 & 62 \\
\hline \multirow{3}{*}{$\begin{array}{l}\text { Mesin } \\
\text { Screw } \\
\text { Pres } 3\end{array}$} & $\begin{array}{l}\text { Worm } \\
\text { Screw }\end{array}$ & 56 & 44 \\
\hline & Besi Shaft & 104 & 65 \\
\hline & Press Cage & 64 & 61 \\
\hline \multirow{3}{*}{$\begin{array}{l}\text { Mesin } \\
\text { Screw } \\
\text { Pres } 4\end{array}$} & $\begin{array}{l}\text { Worm } \\
\text { Screw }\end{array}$ & 54 & 57 \\
\hline & Besi Shaft & 72 & 117 \\
\hline & Press Cage & 74 & 84 \\
\hline \multirow{3}{*}{$\begin{array}{l}\text { Mesin } \\
\text { Screw } \\
\text { Pres } 5\end{array}$} & $\begin{array}{l}\text { Worm } \\
\text { Screw }\end{array}$ & 50 & 56 \\
\hline & Besi Shaft & 80 & 101 \\
\hline & Press Cage & 92 & 80 \\
\hline \multirow{3}{*}{$\begin{array}{l}\text { Mesin } \\
\text { Screw } \\
\text { Pres } 6\end{array}$} & $\begin{array}{l}\text { Worm } \\
\text { Screw }\end{array}$ & 52 & 58 \\
\hline & Besi Shaft & 72 & 83 \\
\hline & Press Cage & 58 & 70 \\
\hline
\end{tabular}

miliki nilai RPN diatas nilai kritis. Maka diambil 3 komponen kritis yaitu besi shaft, worm screw dan press cage. Data frekuensi kerusakan komponen kritis mesin screw press dapat dilihat pada Tabel 2.

Tahap selanjutnya penentuan interval waktu penggantian pencegahan menggunakan metode age replacement untuk mencari umur penggantian optimal, dan juga dicari interval waktu pemeriksaan komponen. Hasil perhitungan penggantian dan pemeriksaan komponen dapat dilihat pada Tabel 3.

Berdasarkan hasil perhitungan interval waktu penggantian dan pemeriksaan, maka dapat diketahui tingkat ketersediaan (availability) dari masing-masing komponen kritis pada mesin screw press. Hasil perhitungan dapat dilihat pada Tabel 4 .

Perhitungan pengendalian persediaan spare part berfungsi untuk menentukan jumlah komponen yang dibutuhkan untuk melakukan tindakan preventive maintenance pada komponen kritis. Hasil rangkuman perhitungan penentuan persediaan spare part dapat dilihat pada Tabel 5.

Tahap selanjutnya adalah melakukan perhitungan tingkat reliability. Rangkuman hasil perhitungan dapat dilihat pada Tabel 6. Metode ini berfungsi untuk me-

Tabel 4. Hasil perhitungan tingkat availability total

\begin{tabular}{cccc}
\hline $\begin{array}{c}\text { Nama } \\
\text { Komponen }\end{array}$ & $\begin{array}{c}\text { Worm } \\
\text { Screw }\end{array}$ & Besi Shaft & Press Cage \\
\hline Mesin SP1 & 0.9779 & 0.979 & 0.9748 \\
Mesin SP2 & 0.9759 & 0.9774 & 0.9799 \\
Mesin SP3 & 0.9731 & 0.9744 & 0.9798 \\
Mesin SP4 & 0.9789 & 0.9852 & 0.9828 \\
Mesin SP5 & 0.9795 & 0.9826 & 0.9831 \\
Mesin SP6 & 0.9745 & 0.9787 & 0.9792 \\
\hline
\end{tabular}

Tabel 5. Hasil perhitungan jumlah kebutuhan persediaan spare part/tahun

\begin{tabular}{cccccc}
\hline $\begin{array}{c}\text { Nama } \\
\text { Komponen }\end{array}$ & $\begin{array}{c}\text { Mesin } \\
\text { SP1 }\end{array}$ & $\begin{array}{c}\text { SP2 } \\
\text { SPin }\end{array}$ & $\begin{array}{c}\text { Mesin } \\
\text { SP3 }\end{array}$ & $\begin{array}{c}\text { Mesin } \\
\text { SP4 }\end{array}$ & $\begin{array}{c}\text { Mesin } \\
\text { SP5 }\end{array}$ \\
\hline $\begin{array}{l}\text { Worm } \\
\text { Screw }\end{array}$ & 9 & 6 & 6 & 8 & 9 \\
Besi Shaft & 4 & 4 & 4 & 4 & 4 \\
Press Cage & 6 & 5 & 4 & 5 & 5 \\
\hline Jumlah & 19 & 15 & 14 & 17 & 18 \\
\hline
\end{tabular}


Tabel 6. Perbandingan sebelum dan sesudah diterapkan preventive maintenance

\begin{tabular}{|c|c|c|c|}
\hline $\begin{array}{l}\text { Nama } \\
\text { Mesin }\end{array}$ & $\begin{array}{c}\text { Nama } \\
\text { KomponenKritis }\end{array}$ & $R(t)$ & $R(t-n T)$ \\
\hline \multirow{3}{*}{$\begin{array}{l}\text { Mesin } \\
\text { Screw } \\
\text { Pres } 1\end{array}$} & Worm Screw & $48.77 \%$ & $93.19 \%$ \\
\hline & Besi Shaft & $36.62 \%$ & $36.62 \%$ \\
\hline & Press Cage & $46.46 \%$ & $98.45 \%$ \\
\hline \multirow{3}{*}{$\begin{array}{l}\text { Mesin } \\
\text { Screw } \\
\text { Pres } 2\end{array}$} & Worm Screw & $38.36 \%$ & $100 \%$ \\
\hline & Besi Shaft & $33.97 \%$ & $100 \%$ \\
\hline & Press Cage & $35.69 \%$ & $100 \%$ \\
\hline \multirow{3}{*}{$\begin{array}{l}\text { Mesin } \\
\text { Screw } \\
\text { Pres } 3\end{array}$} & Worm Screw & $49.31 \%$ & $94.14 \%$ \\
\hline & Besi Shaft & $48.47 \%$ & $95.67 \%$ \\
\hline & Press Cage & $36.03 \%$ & $36.03 \%$ \\
\hline \multirow{3}{*}{$\begin{array}{l}\text { Mesin } \\
\text { Screw } \\
\text { Pres } 4\end{array}$} & Worm Screw & $47.60 \%$ & $92.82 \%$ \\
\hline & Besi Shaft & $49.91 \%$ & $99.83 \%$ \\
\hline & Press Cage & $49.40 \%$ & $92.27 \%$ \\
\hline \multirow{3}{*}{$\begin{array}{l}\text { Mesin } \\
\text { Screw } \\
\text { Pres } 5\end{array}$} & Worm Screw & $32.40 \%$ & $100 \%$ \\
\hline & Besi Shaft & $35.78 \%$ & $35.78 \%$ \\
\hline & Press Cage & $36.34 \%$ & $36.34 \%$ \\
\hline \multirow{3}{*}{$\begin{array}{l}\text { Mesin } \\
\text { Screw } \\
\text { Pres } 6\end{array}$} & Worm Screw & $44.30 \%$ & $99.98 \%$ \\
\hline & Besi Shaft & $39.99 \%$ & $100 \%$ \\
\hline & Press Cage & $38.88 \%$ & $100 \%$ \\
\hline
\end{tabular}

ngetahui tingkat keandalan dari masing-masing komponen mesin screw press. $R(t)$ merupakan tindakan sebelum dilakukan preventive maintenance dan $R(t-n T)$ adalah tindakan sesudah dilakukan preventive maintenance.

\section{Kesimpulan dan Saran}

\section{Kesimpulan}

Berdasarkan hasil pengolahan dan analisa data kerusakan mesin screw press di bab sebelumnya, maka dapat disimpulkan bahwa :

1. Rata-rata perbandingan realibilty sebelum dan sesudah melaksanakan preventif maintenance pada komponen worm screw sebelum $36.39 \%$ dan sesudah $82.87 \%$, pada besi shaft sebelum $34.97 \%$ dan sesudah $66.84 \%$, dan pada press cage sebelum $36.68 \%$ dan sesudah $66.55 \%$.

2. Kebutuhan jumlah spare part mesin screw press adalah komponen Worm Screw 37 unit/tahun, besi Shaft 18 unit/tahun dan Press Cage 24 unit/tahun.
3. Metode yang diusulkan dalam penelitian ini dapat meningkatkan keandalan peralatan ratarata dua kali lipat serta dapat memperkirakan kebutuhan komponen kritis yang harus dibeli oleh perusahaan setiap tahun.

Saran

Pimpinan perusahaan PT. XYZ sebaiknya terus menyosialisasikan dan membudayakan kepada para karyawan tentang kegiatan perawatan pencegahan (preventive maintenance) untuk komponen-kompenen kritis pada setiap mesin Screw Press yang dimiliki sehingga tingkat keandalan mesin secara umum terjaga dengan baik. Di sisi lain, pembelian komponen kritis dapat dilakukan oleh perusahaan sekaligus per tahun untuk kebutuhan selama 12 bulan masa perawatan sehingga langkah ini dapat menurunkan harga pembelian komponen dari agen atau toko karena pembelian dilakukan dalam kuantitas yang banyak.

\section{Daftar Pustaka}

[1] A. Sudradjat, Pedoman Praktis Manajemen Perawatan Mesin Industri, Refika Adi. Bandung, 2011.

[2] P. Tarigan, E. Ginting, and I. Siregar, "Perawatan Mesin Secara Preventive Maintenance Dengan Modularity Design Pada PT. RXY," J. Tek. Ind. $U S U$, vol. 3, 2013.

[3] Assauri and S, Manajemen Produksi dan Operasi, Edisi Revi. Fakultas Ekonomi, Universitas Indonesia, 2008.

[4] Y. Lapai, S. H. Atika, I. H. Lahay, and Hassanuddin, "Evektivitas Mesin dengan Menggunakan Metode Overal Equipment Effetiveness pada PT. XYZ," semanTECH 2019, pp. 289-293, 2019.

[5] S. Oktaria, "Perhitungan dan Analisa Nilai Overall Equipment Effectiveness Pada Proses Awal Pengolahan Kelapa," Skirpsi, 2011.

[6] A. Corder, Teknik Manajemen Pemeliharaan Pemeliharaan, Erlangga. Jakarta, 1992.

[7] S. kenneth Hurth, Prinsip-Prinsip Perancangan Teknik, Erlangga. Jakarta, 2006.

[8] S. Andiyanto, A. Sutrisno, and C. Punuhsingong, "Penerapan Metode FMEA (Failure Mode And Effect Analysis) Untuk Kuantifikasi dan Pencegahan Resiko Akibat Terjadinya Lean Waste," J. Online Poros Tek. Mesin, vol. 6, No 1, 2017. 
[9] Syahruddin, "Analisis Sistem Perawatan Mesin Menggunakan Metode Reliability Centered Maintenance (RCM) sebagai dasar Kebijakan Perawatan yang Oprimal di PLTD," J. Teknol. Terpadu, vol. 1, 2013.

[10] D. . Lasse, Manajemen Peralatan, Rajawali P. Jakarta, 2012.
[11] F. Kurniawan, Manajemen Perawatan Industri, Penerbit G. Yogyakarta, 2013.

[12] C. . Ebeling, An Introduction to Reliability and Maintanability for Engineering, McGraw Hil. New York, 1997. 